IRSTI 55.23 .09

\title{
Preparation method of tungsten oxide and metallic tungsten nano-powders using degreased cotton
}

\author{
A.A. Marhabaeva*, Zh.K. Kalkozova, Ye.S. Mandybayev, \\ A.A. Azatkaliev and Kh.A. Abdullin \\ National Nanotechnology Laboratory of Open Type, \\ 71, al-Farabi ave., 050040, Almaty, Kazakhstan \\ *e-mail: ayymkul.markhabaeva@kaznu.kz
}

\begin{abstract}
A simple method for producing nanopowders of tungsten oxides and metallic tungsten using degreased cotton is proposed. Ammonium tungstate $\mathrm{NH}_{4} \mathrm{~W}_{12} \mathrm{O}_{40}$ was used as a precursor. A medical cotton wool was chosen for experiment. Structural characterizations of nanopowders were performed using X-ray diffraction (XRD) and Raman spectroscopy. Raman Spectra was obtained by NTegra Spectra (NT-MDT), where the light source is blue laser $\sim 473 \mathrm{~nm}$. Analyses of XRD spectra showed that nanopowders have a monoclinic structure. The morphology of synthesized nanopowders was studied using scanning electron microscopy (SEM). The size of nanocrystals was estimated with Scherrer's formula. The effect of annealing temperature on nanoparticle sizes was investigated. The Raman spectra of the obtained samples were studied as a function of the synthesis temperature. In the Raman spectra, broading and red shift of the Raman bands with decreasing size are observed. The most pronounced Raman peaks are assigned to the characteristic vibrations according to the available structural data.
\end{abstract}

Key words: nanopowders, nanoparticles, tungsten oxide, tungsten.

PACS number (s): 61.10.Nz; 61.46.+w; 63.20.-e; 81.05.Hd; 81.20.-n.

\section{Introduction}

Tungsten and its oxides have found wide practical application. Recently, nanoscale materials based on tungsten oxides have particular interest due to their electronic properties. Tungsten oxide is an n-type semiconductor and has excess free electrons; therefore, it has found application as electrochromic [1], photochromic material [2], photocatalyst [3] and gas sensors [4]. Metal oxide/hydroxide composites such as $\mathrm{MnO}_{2}, \mathrm{WO}_{3}$, $\mathrm{NiO}$, and noble metals $(\mathrm{Ag}, \mathrm{Au}, \mathrm{Pt})$ are perspective materials as electrode for supercapacitors [5], since they can improve the specific capacitance, conductivity, chemical and thermal stability of electrode materials. Electrodes based on $\mathrm{WO}_{3} * 2 \mathrm{H}_{2} \mathrm{O}$ show significant power and energy efficiency at high charge/discharge rates [6], energy storage is almost $100 \%$. This makes it possible to use electrodes with a large mass and high volumetric capacity.

There are various methods for producing tungsten oxide nanoparticles, such as sonochemical synthesis [7], precipitation from acid [8], thermal decomposition [9], ion exchange [10], template directed synthesis [11-12] and hydrothermal reactions [13-14]. In this paper, a method for formation of metal and oxide tungsten nanopowders using a fibrous matrix in the form of defatted cotton is proposed. This novel and facile method with the use of degreased cotton was recently applied for the synthesis of cobalt oxide nanoparticles [15].

\section{Materials and methods}

An degreased cotton $(0.5 \mathrm{~g})$ was impregnated with aqueous solution of ammonium metatungstate $\left(\mathrm{NH}_{4}\right)_{6} \mathrm{H}_{12} \mathrm{~W}_{12} \mathrm{O}_{40} * \mathrm{H}_{2} \mathrm{O}(0.01 \mathrm{M})$. The solution with cotton was processed in an ultrasonic bath for 30 minutes to achieve a homogenous substance. Then impregnated with precursor degreased cotton was collected and squeezed. After that the cotton was dried in a vacuum and annealed for 1 hour in air in the tube furnace with a heating rate $1{ }^{\circ} \mathrm{C} / \mathrm{min}$. The annealing temperature was varied from 400 to $700^{\circ} \mathrm{C}$. It is possible to carry out reductive chemical 
reactions using of hydrogen atmosphere during annealing and to obtain nanopowders of tungsten metal.

The crystal structure of the sample was studied by X-ray diffraction (MiniFlex Rigaku) with $\mathrm{Cu} \mathrm{K} \alpha$ radiation. The Raman spectra were taken using an NTegra Spectra (NT-MDT) spectrometer. A blue laser with a wavelength of $473 \mathrm{~nm}$ was used as the excitation source. The irradiation time of the samples by laser radiation was $30 \mathrm{~s}$ and the spot diameter on the sample was $2 \mu \mathrm{m}$. At $100 \%$ intensity, the laser power was $35 \mathrm{~mW}$. Scanning electron microscopy (SEM) images were performed on a Quanta3D200i (FEI) scanning electron microscope.

\section{Results and discussion}

Figure 1 shows the XRD patterns of the $\mathrm{WO}_{3}$ synthesized at temperatures from 400 to $700^{\circ} \mathrm{C}$ (a) and metallic tungsten obtained by reduction of $\mathrm{WO}_{3}$ in hydrogen atmosphere at temperatures 550 to $850^{\circ} \mathrm{C}(\mathrm{b})$. All peaks have a good agreement with the standard monoclinic $\mathrm{WO}_{3}$ spectrum. Moreover, there are no impurity peaks found in the XRD patterns. The obtained results indicate that the wellcrystallized $\mathrm{WO}_{3}$ and metallic $\mathrm{W}$ samples of high purity are produced. According to Scherrer's formula, $\mathrm{D}=0.89 \lambda /(\mathrm{B} \cos \theta)$ (where $\mathrm{D}$ is the mean size of crystallites; $\lambda$ is the X-ray wavelength; $\theta$ is the Bragg angle; and $\mathrm{B}$ is the line diffraction broadening of a peak at half the maximum intensity, which is calculated using obtained XRD pattern), the crystalline size of $\mathrm{WO}_{3}$ is estimated to be $7 \mathrm{~nm}$ in case of annealing temperature $400^{\circ} \mathrm{C}$ and about $300 \mathrm{~nm}$ for $800^{\circ} \mathrm{C}$.

It is known that the smaller crystallite sizes, the broader X-ray peaks. Thus, analyzing XRD data of obtained samples it can be concluded that the sizes of tungsten and tungsten oxide crystals increase with synthesis temperature. However, the formation of the $\mathrm{WO}_{3}$ crystal phase is limited by the temperature of the synthesis reaction, so low-temperature synthesis requires a much longer time. As the annealing temperature is increased, the XRD lines become narrow, hence, this indicates that the crystallite size in the $\mathrm{WO}_{3}$ powder increases.
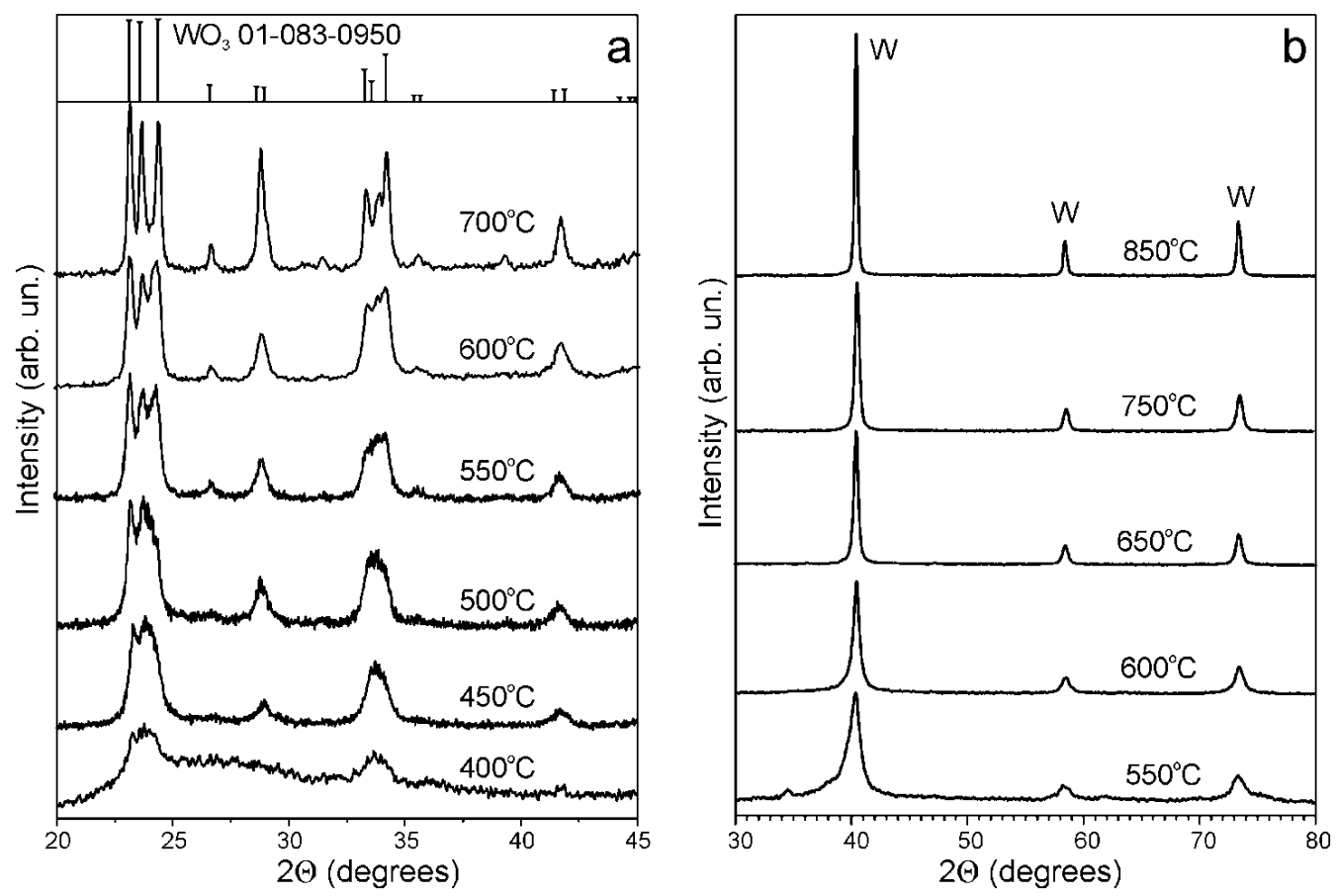

Figure 1 - XRD spectra: a) $\mathrm{WO}_{3}$ obtained at temperatures from 400 to $700^{\circ} \mathrm{C}$, b) $\mathrm{W}$ powder reduced at temperatures from 550 to $850^{\circ} \mathrm{C}$ in hydrogen atmosphere 
The SEM morphology of the synthesized $\mathrm{WO}_{3}$ powders has a good agreement with the X-ray data. It is seen from Fig. 2 that the crystallite sizes of the obtained $\mathrm{WO}_{3}$ samples grow with the synthesis temperature. This is due to the fact that individual nanoparticles begin to interact and form larger crystals with increasing temperature.

Raman spectra of the samples obtained at different temperature conditions were studied.
The main vibrational modes for the $\mathrm{WO}_{3}$ lattice are valence vibrations with a change of bond lengths $(v)$, deformation vibrations with change of the angles between the bonds - planar $(\delta)$ and extra-plane $(\gamma)$. It is known that these modes of tungsten oxide are in the frequency values $\sim 807$, 716, $271 \mathrm{~cm}^{-1}$, which correspond to the stretching of the O-W-O, W-O bonds and O-W$\mathrm{O}$ bending (see Table 1).

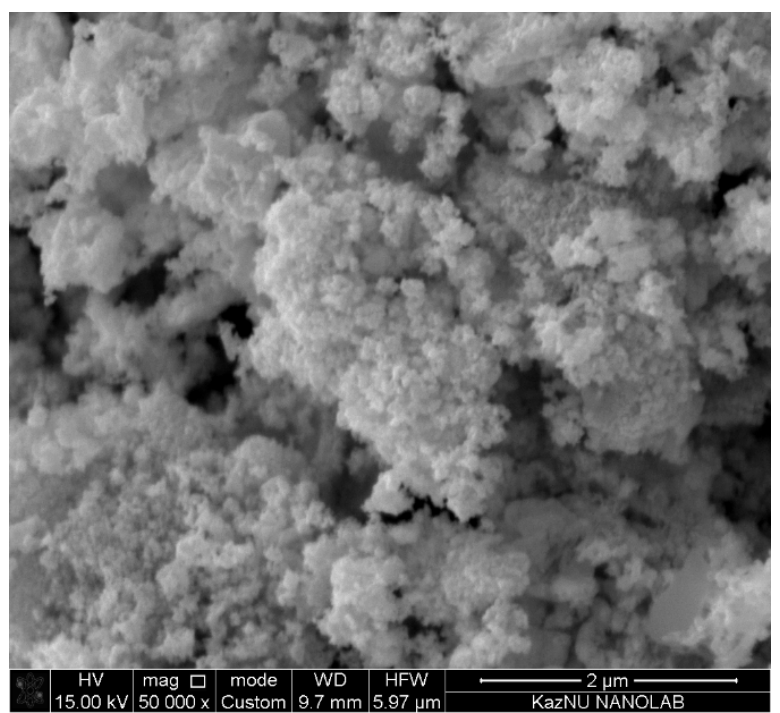

a

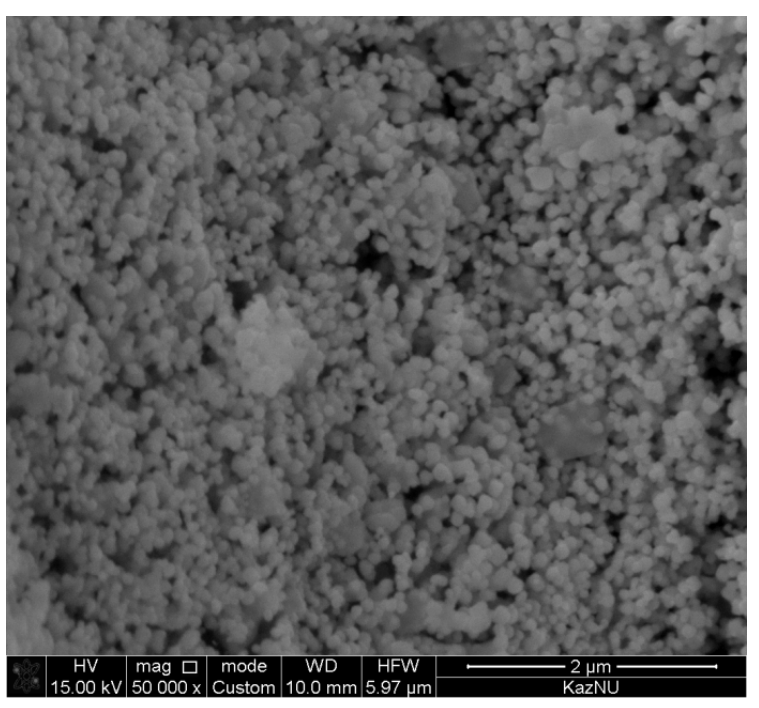

c

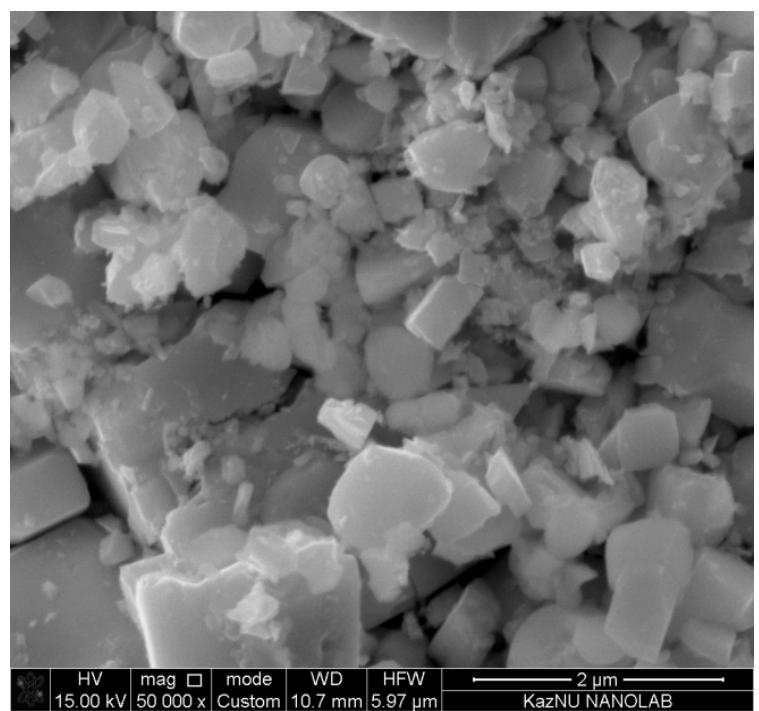

b

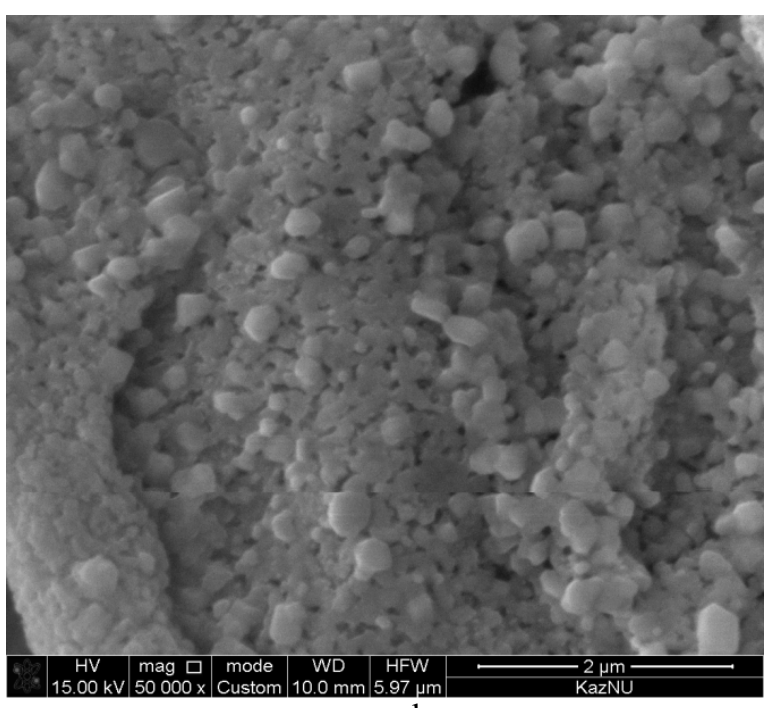

d

Figure 2 - SEM image of $\mathrm{WO}_{3}$ : a) after annealing at $400^{\circ} \mathrm{C}$ and b) $800^{\circ} \mathrm{C}$,

c) metallic $\mathrm{W}$ powders obtained from $\mathrm{WO}_{3}$ reducing at temperature $400^{\circ} \mathrm{C}$ and d) $800^{\circ} \mathrm{C}$ 
Table 1 - Characteristic Raman frequencies $\left(\mathrm{cm}^{-1}\right)$ of the $\mathrm{WO}_{3}$ and literature data

\begin{tabular}{|c|c|c|c|}
\hline Vibrational mode & WO $\left._{\mathbf{3}} \mathbf{4 4 0 0}^{\mathbf{0}} \mathbf{C}\right)$ & WO $\left._{\mathbf{3}} \mathbf{( 8 0 0}^{\mathbf{0}} \mathbf{C}\right)$ & literature \\
\hline $\mathrm{V}(\mathrm{O}-\mathrm{W}-\mathrm{O})$ & 798 & & 804 \\
\hline & & & 715 \\
\hline $\mathrm{V}(\mathrm{W}-\mathrm{O})$ & 683 & - & 436 \\
\hline Vibrations of groups $\mathrm{WO}_{2} \mathrm{~W}$ & - & 372 & 376 \\
\hline$\delta(\mathrm{O}-\mathrm{W}-\mathrm{O})$ & - & 326 & 328 \\
\hline$\delta(\mathrm{O}-\mathrm{W}-\mathrm{O})$ & 321 & 272 & 221 \\
\hline$\delta(\mathrm{O}-\mathrm{W}-\mathrm{O})$ & 251 & & 187 \\
\hline $\mathrm{W}-\mathrm{W}$ & & - & 136 \\
\hline Lattice mode & - & 133 & \\
\hline Lattice mode & 108 & & \\
\hline
\end{tabular}

Raman spectra of $\mathrm{WO}_{3}$ at different annealing temperature are shown in Figure 3 . It is seen from the figure, the main peak around $\sim 800 \mathrm{~cm}^{-1}$ shifts and narrows, depending on the annealing temperature. It is obvious from Table 1 that the position of the Raman lines for $\mathrm{WO}_{3}$ samples synthesized at $400^{\circ} \mathrm{C}$ and $800^{\circ} \mathrm{C}$ are slightly different. It is known that the position of the Raman lines depends on the size of the crystallites, for example, in work [16] it is shown that as the crystallite size increases, the position of the Raman lines shifts toward higher frequencies. This is due to the fact that as the size of the nanocrystals decreases, the surface begins to play an increasingly important role, since the lattice constant and the melting point decrease. These theoretical and experimental data make it possible to explain the dependence of Raman scattering on the size of tungsten oxide nanoparticles. The broadening of the Raman peaks at $\sim 805 \mathrm{~cm}^{-1}, \sim 716 \mathrm{~cm}^{-1}$ and $\sim 271 \mathrm{~cm}^{-1}$ indicates a changing in the vibrational modes of $\mathrm{WO}_{3}$ nanoparticles obtained at low annealing temperatures, and a decrease in the frequency of Raman vibrational modes indicates a softening of the phonon spectrum in nanoparticles $\mathrm{WO}_{3}$.

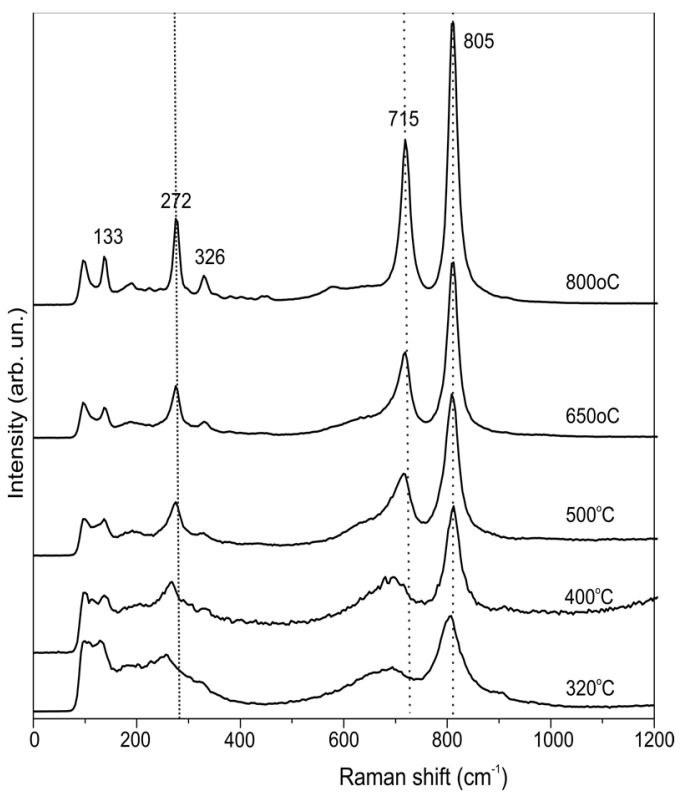

Figure 3 - Raman spectra of the obtained tungsten oxides as a function of the annealing temperature

Figure 4.a shows the dependence of the half-width of the basic mode $E_{g}$ as a function of the annealing temperature. With increasing temperature, the halfwidth of the peaks decreases. The broadening of the 
Raman peaks at $\sim 805 \mathrm{~cm}-1, \sim 716 \mathrm{~cm}-1$, and $\sim 271 \mathrm{~cm}-$ 1 can be attributed to the broadening of the Raman vibrational modes in WO3 nanoparticles obtained at low annealing temperatures. It is also seen that the main peak around $\sim 715 \mathrm{~cm}-1$ shifts towards low frequencies (Figure 4b).

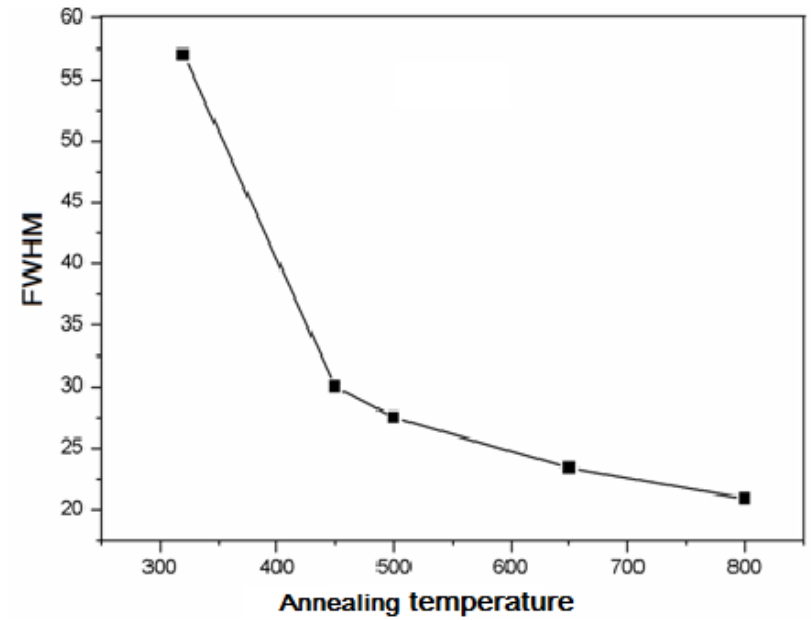

a

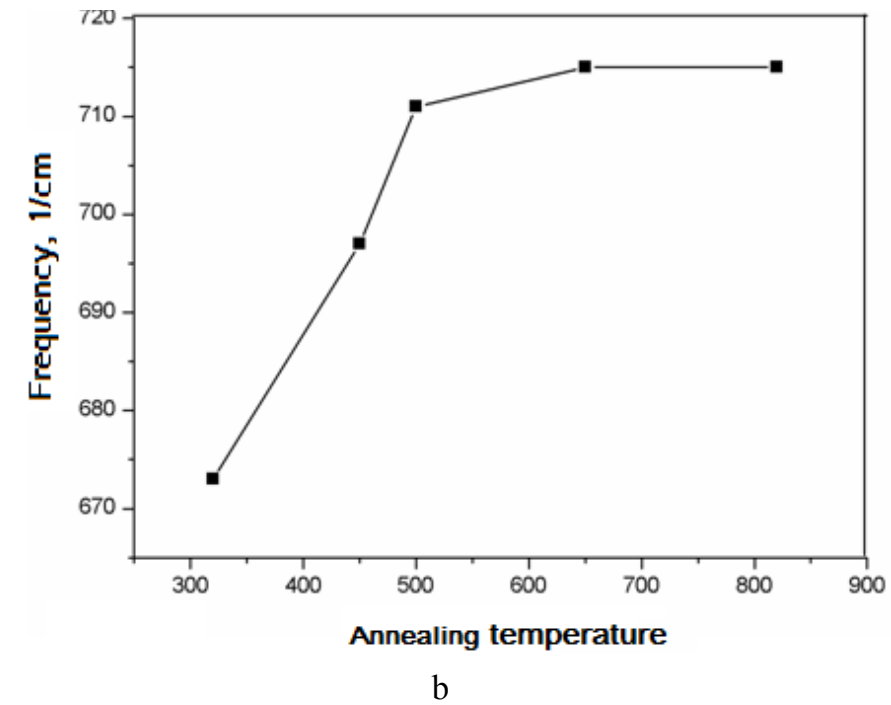

b

Figure 4 - The dependence of the half-width of the $\mathrm{E}_{\mathrm{g}}$ mode about $\sim 805 \mathrm{~cm}^{-1}$ as a function of the annealing temperature (a) and the dependence of the line position about $\sim 715 \mathrm{~cm}^{-1}$ on the annealing temperature (b)

It is known that with decreasing particle sizes to nanometer scales, optical Raman modes shift toward lower wave numbers [17]. The main causes of the Raman redshift of semiconductors can be caused by the size of the crystallites, the temperature (thermal induced expansion and attenuation of bonds), and structural defects [17]. For example, the authors of C. C. Yang and S. Li [18] carried out a great deal of work on the study of Raman spectra as a function of the dimensions of semiconductor nanocrystals. The results show that the Raman frequency decreases with the sizes of nanocrystallites for both narrowgap and wide-gap semiconductors. Vibrational modes associated with the change in bond lengths can shift depending on the size of the crystallites in the red region, and low-frequency deformation vibrational modes, conversely, in the blue region [19]. The red shift of Raman optical modes in particles with small dimensions is usually associated in the literature with surface tension. The amplitude of vibrations of surface atoms is always greater than in the case of atoms in the volume [20-21].

In the framework of the model of spatial correlation [22], an analysis is made of the shift and broadening of the LO line (longitudinal-optical modes) of InP nanocrystals. There was a significant change in the spectral when the crystallite size is less than $10 \mathrm{~nm}$. These changes are explained by the partial amorphization of the near-surface region of the crystals [23].

In [18], the Raman shift in $\mathrm{TiO} 2$ nanoparticles, caused by the effect of particle size reduction, is explained by changes in the force constants and the vibrational amplitudes of the nearest neighboring bonds. The changes are due to the effect of energy deficiency on the order of the binding energy of atoms on the surface and its effect on the force coupling constants between the uncoordinated surface atoms [24]. However, it was suggested in [25] that the observed changes in the Raman spectra with decreasing particle sizes are associated with a change in the stoichiometry and changes in the content of oxygen atoms in $\mathrm{TiO}_{2}$ nanoparticles, rather than associated with any internal stresses or dimensional effects.

\section{Conclusions}

In summary, nanopowders of tungsten oxide and tungsten nanoparticles were successfully prepared by a facile and environmental method using degreased cotton as a supporter. The method makes it possible to obtain nanopowders of refractory metals at low temperatures. 
The structure of the synthesized samples was studied using XRD, SEM and Raman spectroscopy. The dependence of the Raman spectra and X-ray diffraction patterns on the synthesis temperature of the samples was studied. Redshift of the Raman lines and changes in their shape and intensity are induced by the increasing annealing temperature. It can be explained by the increasing crystallite sizes, which also is proved by
XRD data. An analysis of the obtained data allows to conclude that the proposed method is effective for obtaining of tungsten oxide and tungsten metal nanopowders with controlled particle sizes. Moreover, the use of degreased cotton as supporter leads to effective increase of specific surface area, which is important for electrodes in supercapacitors and catalysts.

\section{References}

1. S.S. Fomanjuk, Ju.S. Krasnov, G.Ja. Kolbasov, V.N. Zajchenko. Jelektrohromnye svojstva i nanostruktura amorfnyh plenok oksida vol'frama // Ukr. Him. Zhurn. - 2008. - Vol. 74. - No. 3. - P. 55-59. (In Russian)

2. M. Sun, N. Xu, Y.W. Cao, J.N. Yao, E.G. Wang. Nanocrystalline tungsten oxide thin film: preparation, microstructure, and photochromic behavior // J. Mater. Res. -2009. -No. 15. -P. 927-933.

3. G.R. Bamwenda, H. Arakawa, The visible light induced photocatalytic activity of tungsten trioxide powders // Appl. Catal. 2001. -Vol. 210. -P. 181-191.

4. Jimenez-Cadena, G. Riu, J. Rius. Gas sensors based on nanostructured materials //Analyst, - 2007. - Vol. 132. P. 1083-1099.

5. Y. Yan, T. Wang, X. Li, H. Pang, H. Xue. Noble metal-based materials in high-performance supercapacitors // Inorg. Chem. Front., - 2017. -Vol. 4. -P. 33-51.

6. J.B. Mitchell, W.C. Lo, A. Genc, J. LeBeau, V. Augustyn. Transition from battery to pseudocapacitor behavior via structural water in tungsten oxide // Chem. Mater., - 2017. - Vol. 29. - P. 3928.

7. Yu. Koltypin, S.I., Nikitenko, A. Gedanken. The sonochemical preparation of tungsten oxide nanoparticles // J. Mater. Chem. - 2002. - Vol. 12. - P. 1107-1110.

8. S. Supothina, P. Seeharaj, S. Yoriya, M. Sriyudthsak. Synthesis of tungsten oxide nanoparticles by acid precipitation method // Ceramics international, - 2007. - P. 931-936.

9. Y. Xu, S. Carlson, R. Norrestam // J. Solid State Chem. -1997. -Vol. 132. -P. 123.

10. Y.G. Choi, G. Sakai, K. Shimanoe, N. Miura, N. Yamazoe. Preparation of aqueous sols of tungsten oxide dehydrate from sodium tungstate by an ionexchange method // Sens. Actuators B, - 2002. -Vol. 87. -P. 63-72.

11. B.B. Lakshmi, P.K. Dorhout, C.R. Martin sol-gel template synthesis of semiconductor nanostructures // Chem. Mater., - 1997. - Vol. 9. - P. 857.

12. B. C. Satishkumar, A. Govindaraj, M. Nath, C. N. R. Rao. Synthesis of metal oxide nanorods using carbon nanotubes as templates // J. Mater. Chem. -2000. - Vol. 10. - P. 2115.

13. Li, X. L.; Liu, J. F.; Li, Y. D. // Large-Scale Synthesis of Tungsten Oxide Nanowires with High Aspect Ratio. Inorg. Chem. $-2003 .-42 .-921$.

14. X. W. Lou, H. C. Zeng. An inorganic route for controlled synthesis of $\mathrm{W}_{18} \mathrm{O}_{49}$ nanorods and nanofibers in solution // Inorg. Chem. - 2003. - Vol.42. - P. 6169.

15. H. Xu, L. Gao, Q. Zhang, J. Li, J. Diwu, X. Chou, J. Tang, Ch. Xue. Preparation method of $\mathrm{Co}_{3} \mathrm{O}_{4}$ nanoparticles using degreased cotton and their electrochemical performances in supercapacitors // Journal of Nanomaterials, - 2014. Vol. 2014. -P. 723057.

16. Y. Gao, X. Zhao, P. Yin, F. Gao. Size-Dependent Raman Shifts for nanocrystals // Scientific Reports, -2016. Vol. 6. -P.20539.

17. M. Boulovan, G. Lucazeauw. Crystallite nanosize effect on the structural transitions of $\mathrm{WO}_{3}$ studied by Raman spectroscopy // Journal of Solid State Chemistry, - 2002. - Vol. 167. - P. 425-434;

18. C. C. Yang, S. Li. Size-dependent Raman red shifts of semiconductor nanocrystals // J. Phys. Chem. B. -2008. - Vol. 112. - P. 14193-14197.

19. W.F. Zhang, Y. L. He, M. S. Zhang, Z. Yin, Q. Chen. Raman scattering study on anatase $\mathrm{TiO}_{2}$ nanocrystals // J. Phys. D: Appl. Phys. -2000. - Vol.33. - P.912-916.

20. Z. Iqbal, S. Veprek, A. Sarott. Effect of grain boundaries on the Raman spectra, optical absorption, and elastic light scattering in nanometer-sized crystalline silicon // J. Phys. -1982. - Vol. 377. - P. 15;

21. E. Anastassakis, E. Liarokapis. Polycrystalline Si under strain: Elastic and latticedynamical considerations // J. Appl. Phys., -1987. - Vol.62. - P. 3346-3352.

22. A.V. Korotcov, Y.S. Huang, D.S. Tsai, K.K. Tiong. Raman scattering characterization of vertical aligned 1D $\mathrm{IrO}_{2}$ nanocrystals grown on single crystal oxide substrates // Solid State Commun., -2006. - Vol.137. - P.310.

23. H.C. Choi, Y.M. Jung, S.B. Kim. Size effects in the Raman spectra of $\mathrm{TiO}_{2}$ nanoparticles // Vib. Spectrosc. 2005. - Vol.37. - P. 33-38.

24. M. X. Gu, L. K. Pan, B. K. Tay, Chang Q. Sun. Atomistic origin and temperature dependence of Raman optical redshift in nanostructures: a broken bond rule // J. Raman Spectrosc. -2007. - Vol.38. - P. 780-788.

25. J.C. Parker, R.W. Siegel. Calibration of the Raman spectrum to the oxygen stoichiometry of nanaphase $\mathrm{TiO}_{2} / /$ Appl. Phys. Lett. - 1990. -Vol.57. -P. 943-945. 